\title{
The impact of child abuse and neglect training on knowledge and awareness in university students
}

\author{
Husniye ALTAN $^{1}\left(\mathbb{D}\right.$, Figen SAHIN DAGLI ${ }^{2}$ (D) Isil Irem BUDAKOGLU ${ }^{3}$ \\ 1 Department of Child Health and Disease, Faculty of Medicine, Yuksek Ihtisas University, Liv Hospital, Ankara, Turkey. \\ 2 Department of Social Pediatrics, Faculty of Medicine, Gazi University, Ankara, Turkey. \\ 3 Department of Medical Education, Faculty of Medicine, Gazi University, Ankara, Turkey.
}

Corresponding Author: Husniye ALTAN

E-mail: husniyealtan@yahoo.com

Submitted: $05.01 .2020 \quad$ Accepted: 25.03.2020

\section{ABSTRACT}

Objective: Child abuse and neglect are considered public health issues by authorities such as the World Health Organization (WHO). This study evaluated the effectiveness of the trainings given to university students.

Materials and Methods: In this study, we trained university students at Gazi University who are likely to deal with child abuse cases after graduation. By developing two scales, Child Abuse and Neglect Awareness Scale (CANA-S) and Child Abuse and Neglect Knowledge Test (CANK-T), to assess students' knowledge and awareness levels regarding child abuse and neglect, we evaluated the training's impact.

Results: We assessed the knowledge and awareness levels of 43 students before and after training by using our scales, The knowledge level has improved significantly in all groups regardless of age, sex, and department. Similarly, the awareness level has also risen significantly, except regarding the physical abuse subscale.

Conclusion: Overall awareness after education was significant among students from the health and social sciences departments. Total awareness scores did not increase significantly among law students. Measuring and disseminating the effectiveness of these trainings through proper prevention programs will be effective in reducing child abuse in the future.

Keywords : Awareness, Child abuse and neglect, Training program for university students, Knowledge, Scale

\section{INTRODUCTION}

The World Health Organization (WHO) defines child abuse and neglect as "all physical and/or emotional ill-treatment, sexual abuse, neglect or negligence and commercial or other exploitation, which results in actual or potential harm to the child's health, survival, development or dignity in the context of a relationship of responsibility, trust or power" [1]. WHO found that $20 \%$ of women and $5 \%-10 \%$ of men were sexually abused as children, and $25 \%-50 \%$ of all children were physically abused [2]. In 2012, public institutions and child protection centers in the US received 3.4 million applications for abused and neglected children [3]. Authorities such as the WHO and the American Centers for Disease Control and Prevention (CDC) consider the abuse and sexual exploitation of children as public health issue $[4,5]$. Many organizations have focused on training programs for the prevention of child abuse and neglect [6]. Public health policies should include the pre-emptive prevention of child abuse and neglect, as well as support for children's healthy development, which can be achieved through primary methods of prevention and maintaining existing approaches to ameliorate the effects of child abuse and neglect [6].

During the 1980s, "Child-oriented prevention" was a primary prevention method. This school-centered empowerment program for the prevention of child sex abuse has the following general goals: 1) to help children recognize potential situations of abuse and become aware of exploiters, 2) to support children's rejection of sexual requests, 3) to teach children to resist by avoiding exploiters, 4) to encourage children to report previous or current abuse to trusted authority figures, and 5) to explain to children that inappropriate touching and secrets are not their responsibility [7]. Attending such programs has been shown to increase children's awareness concerning protective behaviour against sexual abuse, but how well such programs prevent sexual abuse remains unclear $[8,9]$. A primary prevention method, the "parent-oriented prevention method" instructs the adults surrounding the child, such as his/her parents and teachers [10]. The "community-oriented prevention method" works to increase public awareness by focusing on not only the child

How to cite this article: Altan H, Sahin Dagli F, Budakoglu I I. The impact of child abuse and neglect training on knowledge and awareness in university students. Marmara Med J 2020;33: 48-53 doi: 10.5472/marumj. 738395 
and the adults in his or her immediate surroundings, but also on the rest of the community through public trainings, and media campaigns (television, radio, newspaper, posters, and announcements) [11].

With the increase in child abuse cases in Turkey the need for the prevention of child abuse, as well as the demand for trained, sensitive, and educated individuals working in career fields focused on children has increased. Since 2005, university students have been trained by various departments on child abuse and neglect resulting from the collaboration of the Division of Social Pediatrics of Gazi University, School of Medicine and the Turkish Society for the Prevention of Child Abuse and Neglect (TSPCAN). Implemented trainings and programs on the prevention of child abuse must be grounded on a firm scientific foundation, with reliable data and evidence of significant benefits.

This study evaluated the impact of the training using the Child Abuse and Neglect Awareness Scale (CANA-S) [12] and the Child Abuse and Neglect Knowledge Test (CANK-T) [13] on the awareness of child abuse and neglect. We also evaluated whether this training increased the relevant knowledge levels of the participants or not.

\section{MATERIALS and METHODS}

\section{Assessment Tools}

Child Abuse and Neglect Awareness Scale: The CANA-S comprises four subscales (physical abuse, sexual abuse, emotional abuse, and neglect); of the 20 questions, 11 were phrased negatively and 9 positively. All items were presented as Likert scales, with five answer choices (ranging from "not appropriate at all" to "definitely appropriate"). Items were prepared and the reliability and validity were tested during and after the pilot study. Factor analysis was completed for construct validity, and experts were consulted to obtain content validity. In the reliability analysis, Cronbach's alpha value was 0.768 and the correlation coefficient was $r=0.204$. The test-retest analysis found was to be significant $\mathrm{p}=0.045$ [12].

Child Abuse and Neglect Knowledge Test: The CANK-T had 50 multiple choice questions with 5 answer choices each. Reliability and validity testing were completed during and after the preparation of items. The knowledge test was validated by preparing a table of specifications for each lesson and by creating common goals based on the Bloom Taxonomy for all lessons that concerned the child abuse and neglect and expected behaviour education according to the Bloom Taxonomy. The Kuder Richardson-20 reliability coefficient and Pearson's correlation test were used to measure the reliability of the information test. The Kuder Richardson-20 reliability coefficient was calculated separately for test-retest and resulted in 0.943 and 0.918 , $\mathrm{r}=0.443$, and $\mathrm{p}=0.011$; the information test was found reliable [13].

\section{Application and Population of the Study}

The CANA-S and CANK-T forms were distributed, to the participants before the training began. Just after the last lesson of the 12-week training program, the forms were again distributed to the participants under supervision.

The study population was created by voluntary response sampling and comprised of 145 voluntary college students from medicine, social services, law, psychology, child development, guidance and psychological counseling, sociology, education, midwifery, and nursing departments. The training was advertised before it started both on the website of the Turkish Society for the Prevention of Child Abuse and Neglect and social media.These students had participated in trainings on child abuse and neglect with the collaboration of Turkish Society for the Prevention of Child Abuse and Neglect and the Division of Social Pediatrics of Gazi University, School of Medicine during the 2014-2015 academic year. All in all, 48 students participated in the training for 8 weeks or more; 44 students took both the pre-test and post-test, but the research group consisted of 43 students because one student had been removed as per the exclusion criteria.

\section{Exclusion Criteria}

Those who participated in the training for less than 8 weeks were not included in the study as they missed most of the topics addressed, which would have had an impact on the measure of the success of the training.

\section{Study Duration and Setting}

Approval for the study was obtained from the Turkish Society for the Prevention of Child Abuse and Neglect and Division of Social Pediatrics of Gazi University, Scool of Medicine and the Gazi University Ethics Committee (number 77082166604.01.02-18605).

The study was conducted in the Divisions of Social Pediatrics and Medical Education of Gazi University, School of Medicine between 01.01.2014 and 30.05.2014.

\section{Training Application and Scope}

The training that has been underway since 2005 was created in collaboration with the Division of Social Pediatrics of Gazi University, School of Medicine and Turkish Society for the Prevention of Child Abuse and Neglect, and the trainings were provided by the above mentioned society instructors for voluntary students on child abuse and neglect for 12 weeks, once a week for 2 hours.

\section{Statistical Analysis}

We examined whether continuous variables were distributed according to normal distribution by using a KolmogorovSimonov test and the homogeneity of the variances through a Levene test. Descriptive statistics are shown in the form of median minimum-maximum (min-max) values for continuous variables and as number of observations and (\%) 
for nominal scaled data. By using the Wilcoxon signed-rank test, we investigated whether the groups underwent statistically significant changes before and after training according to the CANK-T and CANA-S subscales and total scale points.

Also we evaluated the importance of the extent of difference among the departments of the participants before and after training on the CANK-T, CANA-S subscale and total scales using the Kruskal-Wallis test.

A Spearman correlation test determined whether the correlation between the change in level of knowledge with age before and after training and the change in the subscale of awareness and the total points was statistically significant. For $\mathrm{p}<0.05$ the results were considered statistically significant. In this study, Kuder Richardson-Formula 20 test was intrumentalized for the reliability test of CANK-T and the program SPSS for Windows 11.5 was used for data analysis.

\section{RESULTS}

\section{Demographic Findings}

Based on their departments, the students were categorized into three groups: Healthcare Sciences, Law, and Social Sciences. The demographic findings are shown in Table I.

Table I. Demographic characteristics of the students

\begin{tabular}{|lc|}
\hline Students & $\mathbf{n}=\mathbf{4 3}$ \\
\hline Age (average \pm standard deviation) & $21.1 \pm 6.2$ \\
\hline Gender & \\
\hline Female & $40(93.0 \%)$ \\
\hline Male & $3(7.0 \%)$ \\
\hline Department & $11(25.6 \%)$ \\
\hline Health Sciences & $1(2.3 \%)$ \\
\hline Medicine & $9(21.0 \%)$ \\
\hline Social Services & $1(2.3 \%)$ \\
\hline Nursing-Midwifery & $5(11.6 \%)$ \\
\hline Law & $27(62.8 \%)$ \\
\hline Social Sciences & $9(21.0 \%)$ \\
\hline Psychology & $11(25.6 \%)$ \\
\hline Guidance and Psychological Counseling & $1(2.3 \%)$ \\
\hline Sociology & $6(13.9 \%)$ \\
\hline Child Development
\end{tabular}

\section{Awareness Subscale before and after Training and Total Points for All Students}

The percentage of change before and after training scores for all students reflected in the total awareness scale points were found statistically significant (Table II). The awareness point before having the training was 85 out 100 which showed us that they had already gained some knowledge concerning the issues covered in the training. By perfoming studies with various groups, the effectiveness of the scale would be better understood. Whereas points regarding the neglect, sexual abuse, and emotional abuse subscales rose significantly for all students after having the training, the physical abuse subscale did not increase significantly (Table II).

Table II. Pre and post-training awareness subscales and total scores for all students

\begin{tabular}{lccc}
\multicolumn{1}{c}{$\begin{array}{c}\text { Awareness } \\
\text { subscales }\end{array}$} & $\begin{array}{c}\text { Before-Training } \\
\text { Median (min-max) }\end{array}$ & $\begin{array}{c}\text { After-Training } \\
\text { Median (min-max) }\end{array}$ & p value $^{\mathrm{a}}$ \\
Neglect & $23(13-25)$ & $23(19-25)$ & $\mathbf{0 . 0 1 8}$ \\
Physical Abuse & $23(19-25)$ & $24(16-25)$ & 0.275 \\
Sexual Abuse & $21(16-24)$ & $22(17-24)$ & $<\mathbf{0 . 0 0 1}$ \\
Emotional Abuse & $19(14-24)$ & $20(16-24)$ & $\mathbf{0 . 0 3 0}$ \\
\hline Total & $85(75-95)$ & $89(75-95)$ & $<\mathbf{0 . 0 0 1}$ \\
\hline
\end{tabular}

${ }^{a}$ Wilcoxon Signed Rank Test; values in bold indicate statistical significance

\section{Awareness Subscales and Total Results before and after Training According to Departments}

After having the training, the scores for the neglect subscale rose significantly among the social sciences students, while they did not increase among the health sciences and law students (Table III). For the sexual abuse subscale, the scores after having the training increased significantly among health and social sciences students, whereas they did not rise for law students (Table III).

Table III. Pre and post-training awareness subscales and total scores of students according to their departments

\begin{tabular}{lcccc}
\multicolumn{1}{c}{ Variable } & $\begin{array}{c}\text { Before-Training } \\
\text { Median (min- } \\
\text { max) }\end{array}$ & $\begin{array}{c}\text { After-Training } \\
\text { Median (min- } \\
\text { max) }\end{array}$ & p value $^{\mathrm{a}}$ & p value $^{\mathrm{b}}$ \\
Neglect & & & & 0.613 \\
Health Sciences & $23(19-25)$ & $24(19-25)$ & 0.862 & \\
Law & $24(18-25)$ & $24(24-25)$ & 0.285 & \\
Social Sciences & $22(13-25)$ & $23(20-25)$ & $\mathbf{0 . 0 2 8}$ & \\
\hline Physical Abuse & & & & 0.315 \\
Health Sciences & $23(21-25)$ & $24(20-25)$ & 0.089 & \\
Law & $24(23-25)$ & $24(23-25)$ & 1.000 & \\
Social Sciences & $24(19-25)$ & $24(16-25)$ & 0.737 & \\
\hline Sexual Abuse & & & & 0.420 \\
Health Sciences & $20(16-24)$ & $23(19-24)$ & $\mathbf{0 . 0 2 1}$ & \\
Law & $21(17-21)$ & $21(19-22)$ & 0.593 & \\
Social Sciences & $21(17-24)$ & $22(17-24)$ & $\mathbf{0 . 0 0 3}$ & \\
\hline Emotional Abuse & & & & 0.928 \\
Health Sciences & $19(16-23)$ & $20(17-22)$ & 0.101 & \\
\hline Law & $19(16-21)$ & $20(19-21)$ & 0.414 & \\
Social Sciences & $19(14-24)$ & $19(16-24)$ & 0.159 & \\
\hline Total & & & & 0.835 \\
Health Sciences & $87(75-91)$ & $91(75-95)$ & $\mathbf{0 . 0 2 8}$ & \\
\hline Law & $88(79-90)$ & $91(86-91)$ & 0.279 & \\
\hline Social Sciences & $85(76-a 95)$ & $89(75-94)$ & $\mathbf{0 . 0 2 4}$ & \\
\hline & & & \\
\hline
\end{tabular}

apercent of change (pre-post) before and after training within different departments, Wilcoxon signed rank test; values in bold indicate statistical significance

'Increase in awareness scores before and after training within departments, Kruskal-Wallis test; values in bold indicate statistical significance 
On the other hand, the scores of emotional and physical abuse subscale did not step-up significantly for any student after the training (Table III).

The total awareness scores increased among the health and social sciences students after having training although they did not rise among law students (Table III).

\section{Test Scores before and after Training on the Knowledge Test for All Students According to Major}

The knowledge test scores after having the training increased in all students regardless of their departments. (Table IV).

In this study, the reliability of CANK-T was measured as 0.584 before the training and 0.636 after the training.

Table IV. Scores for the knowledge test before and after training according to major

\begin{tabular}{lcccc} 
Variables & $\begin{array}{c}\text { Before-Training } \\
\text { Median (min-max) }\end{array}$ & $\begin{array}{c}\text { After-Training } \\
\text { Median (min-max) }\end{array}$ & $\begin{array}{c}\mathbf{p} \\
\text { value }^{\mathrm{a}}\end{array}$ & $\begin{array}{c}\mathbf{p} \\
\text { value }\end{array}$ \\
Department & & & & $0.077^{\mathrm{b}}$ \\
Health Sciences & $35(26-41)$ & $39(36-45)$ & $\mathbf{0 . 0 0 5}$ & \\
Law & $33(30-34)$ & $40(38-43)$ & $\mathbf{0 . 0 4 2}$ & \\
Social Sciences & $35(25-41)$ & $39(25-46)$ & $<\mathbf{0 . 0 0 1}$ & \\
\hline Overall & $34(25-41)$ & $39(25-46)$ & $<\mathbf{0 . 0 0 1}$ & \\
\hline
\end{tabular}

apercentage of change (pre-post) before and after training., Wilcoxon signed rank test; values in bold indicate statistical significance

bercentage of change (pre-post) before and after training increase in awareness scores within departments, Kruskal-Wallis test

\section{DISCUSSION}

Child abuse and neglect is a significant issue, that can be transferred from one generation to another. It negatively affects childhood as well as adult life. A preventive method is providing an education on child abuse in order to increase the awareness of parents and individuals who deal with children and society as a whole.

The method for studying cognitive awareness requires learning how to learn, focusing on one's attention, planning what needs to be done step by step, evaluating each step of the learning process, and correcting and organizing [14]. We used the CANA-S to observe how individuals perceive child abuse and neglect, and also learn their level of comprehension, their knowledge and ideas on the topic.

In our literature review, we found school-oriented prevention programs for kindergartens, elementary and middle schools, and a few high schools. However, there were no such programs for college students $[9,15]$.

In the majority of studies we reviewed, we observed that school-based prevention training programs significantly increased children's knowledge and behaviour [16, 17]. When students actively participated in the training, an increase in both knowledge and protective behaviour scores was found higher among different age groups [18]. Standardized scales, short stories, and certain images were used before and after the training in kindergartens, elementary and middle schools so as to evaluate the knowledge at school-based trainings. High school students were assessed using only question-based knowledge tests such as The Sexual Attitudes Survey and its four subscales [19]. In our study, we administered the CANK-T twice, once before and once after the 12-week child abuse and neglect training. After the 12 week-training, the scores for knowledge were higher. In some studies, in order to evaluate the level of information recall, assessments were conducted only 3-12 months after the training, but we found no consensus on the ideal waiting period [9]. A study investigating the information recall found no difference between 6 months and 12 months after training [20]. In our study, the knowledge assessment was conducted right after the 12-week training, since it would have been difficult to reach voluntary students at any subsequent time. Furthermore, since the primary purpose of the study was to evaluate how much of the information had been understood, there was no need for a scale using long-term reminder.

Our study demonstrated that the 12-week child abuse and neglect training was an efficacious one achieving an increase in the total awareness and knowledge levels of all students participating in the training.

When the scores before the training and after the training were compared for the physical abuse subscale, no statistically significant increase was found. This is attributable to the already high before-training awareness scores, suggesting that physical abuse may be easier to identify from other types of abuse as the former often has visible indications.

The significant high scores for the total awareness of this issue among health and social sciences students when compared with those of law students may stem from students who are likely to work in child-related occupations in the future have a great interest in child abuse and neglect training than others. Additionally, it can also be explained by the low rate of law students who attended the training. There was no statistical difference between the increase in awareness in the emotional abuse and physical abuse subscales in terms of students' majors. This suggested that emotional abuse was difficult to understand and prove. Why the physical abuse awareness did not increase can be explained by all three majors having high awareness scores on entering the training that had little room for meaningful increase.

In some studies, an important link has been found between age and rise in knowledge through education $[21,22]$. On the other side, in a study where elementary school students aged 5-7 and 8-13 year olds were compared, it was observed that the older students learning was faster and more thorough than in the younger ones [23]. Yet, some studies did not find any difference for age, regarding learning and increasing knowledge on this issue[16-18, 24]. In previous studies, the groups that received trainings comprised of high school or younger students, while our study group consisted of university students of similar age. For this reason, it was not possible to comment on age and increase in knowledge regarding our study. 
The reliability of CANK-T used in our study was found low according to the scale we implemented which might stem from the absence of the voluntary students in trainings.

When scores in knowledge and awareness based on gender has been evaluated, as the women made up 93\% $(n=40)$ of the study population, no valued statistical comparison could be made. Work to increase male students' participation in future trainings must be put forward. If more male students were more informed about this topic, their awareness and participation could have increased.

As we demonstrated in our study, CANK-T and CANA-S [12,13] scales developed by us, authors of this study, are applicable during trainings on the child abuse and neglect issue.

\section{Limitations of the Study}

The limitations include the number of drop-outs which is inevitable in view of the voluntary nature of participation in the study and the low number of students who took the final test. Because Turkish Society for Prevention of Child Abuse and Neglect trainings will continue in the future, this limitation may be overcomed by adjusting future trainings.

Child abuse prevention trainings and programs must be implemented with a strong scientific basis, reliable data, and proof of significant benefit.

\section{Compliance with Ethical Standards}

Funding: The study was not supported by any funds.

Conflict of Interest: The authors have no conflicts of interest to declare.

Ethical approval: Approval for the study was obtained from the Turkish Society for the Prevention of Child Abuse and Neglect and Division of Social Pediatrics of Gazi University, Scool of Medicine and the Gazi University Ethics Committee (number 77082166-604.01.02-18605).

Informed consent: Informed consent was obtained from all individual participant included in the study.

Authors' Contrubition: Concept and Design - HA, FSD, IIB; Supervision - FSD, IIB; Resources - HA, FSD, IIB; Materials HA, FSD, IIB; Data Collection and Processing - HA, IIB; Analysis and Interpretation - IIB, HA; Literature Search - HA; Writing Manuscript - HA; Critical Review - FSD, IIB

\section{REFERENCES}

[1] World Health Organisation. From the Report of the Consultation on Child Abuse Prevention, 1999 Geneva 29-31 March. Available from: http://apps.who.int/iris/ handle/10665/65900. Accessed 13 April 2015.

[2] Dinesh S, Bellis M, Hughes K, Gilbert R, Mitis F, Galea G. WHO, European-Report-on-Preventing-Child-Maltreatment. 2010. Available from: http:// http://www.euro.who.int/_data/ assets/pdf_file/0017/307520 Accessed 12 May 2015.

[3] U.S. Department of Health and Human Services, Administration for Children and Families, Administration on Children, Youth and Families, Children's Bureau. Child Maltreatment 2012 [online]. Washington, DC: Government Printing Office; 2012. Available from:http://www.acf.hhs.gov/ sites/default/files/cb/cm2012.pdf. Accessed 14 February 2015.

[4] Whitaker DJ, Lutzker JR, Shelly GA. Child maltreatment prevention priorities at the Centers for Disease Control and Prevention. Child Maltreat 2005;10:224-59. doi:10.1177/107.755.9505274674.

[5] World Health Organization. World Health Report. 2006. Available from: http:/ / www.who.int/whr/2006/whr06_ en.pdf. Accessed 12 May 2015.

[6] Janet S, Linda AV, Mercy JA, Turner S, Kaufmann R, Popovic T. CDC grand rounds: creating a healthier future through prevention of child maltreatment. MMWR Morb Mortal Wkly Rep 2014;28:12.

[7] Wurtele SK. Behavioral approaches to educating young children and their parents about child sexual abuse prevention. JOBA-OVTP 2008;1:52-64. doi: 10.1037/h0100434 issn Print: 2155-8655.

[8] Reynolds AJ, Robertson DL. School-based early intervention and later child maltreatment in the Chicago Longitudinal Study. Child Dev 2003;74:3-26. doi10.1111/1467-8624.00518.

[9] Zwi K, Woolfenden S, Wheeler DM, O’Brien T, Tait P, Wiliams KJ. School-based education programmes for the prevention of child sexual abuse (Review) Cochrane Database of Systematic Review, 2007; 3 Art. No:CD004380. https://doi.org/10.4073/ csr.2007.

[10] Prinz RJ, Sanders MR, Shapiro CJ, Whitaker DJ, Lutzker JR. Population-based prevention of child maltreatment: the U.S. Triple P System Population Trial. Prev Sci 2009;10:1-12. DOI 10.1007/s11121.009.0123-3.

[11] Daro D, Dodge KA. Creating community responsibility for child protection: possibilities and challenges. Future Child 2009;19:67-93. doi: 10.1353/foc.0.0030.

[12] Altan H, Budakoglu II, Dagli FS. Measuring awareness about child abuse and neglect: validity and reliability of a newly developed tool Child Abuse and Neglect Awareness Scale. The Turk J Pediatr 2018; 60: 392-399. doi: 10.24953/ turkjped.2018.04.006.

[13] Altan H. Üniversite öğrencisi gençlere çocuk istismarı ve ihmali konusunda yaplan eğitimin bilgi ve farkındalıklarına etkisi. PhD Thesis, Gazi University Institute of Health Sciences, Department of Social Pediatrics, Ankara; 2015.

[14] Paris SG, Winograd P. How metacognition can promote academic learning and instruction. In: Jones BJ, Idol L, eds., Dimensions of thinking and cognitive instruction Hillsdale, NJ: Lawrence Erlbaum Associates, 1990:15-51.

[15] Mytton J, DiGuiseppi C, Gough D, Taylor R, Logan, S. Schoolbased secondary prevention programmes for preventing violence. Cochrane Database of Syst Rev 2006;3:CD004606. doi: 10.1002/ 14651858.CD004606.pub2.

[16] Harvey P, Forehand R, Brown C, Holmes T. The prevention of sexual abuse: Examination of the effectiveness of a program with kindergarten-age children. Behav Ther 1988;19:429-35. doi:10.1016/S0005-7894(88)80014-5. 
[17] Kolko DJ. Classroom training in sexual victimization awareness and prevention skills: An extension of the Red Flag/ Green Flag People program. J Fam Violence 1989;4:25-45. doi:10.1007/BF00985655.

[18] Blumberg EJ. The touch discrimination component of sexual abuse prevention training: Unanticipated positive consequences. J Interpers Violence 1991;6:12-28. doi: 10.1177/088.626.091006001002.

[19] Pacifici C, Stoolmiller M, Nelson C. Evaluating a prevention program for teenagers on sexual coercion: a differential effectiveness approach. J Consult Clin Psychol 2001; 69:5529. doi:10.1037/0022-006X.69.3.552.

[20] Hazzar A, Webb C, Kleemeier C, Angert L, Pohl J. Child sexual abuse prevention: Evaluation and one-year follow-up. Child Abuse Negl 1996;15:123-38. doi:10.1016/01452134(91)90097-W.
[21] Tutty LM. Child sexual abuse prevention programs: evaluating 'Who Do You Tell'. Child Abuse Negl 1997;21:869-81. doi:10.1016/S0145-2134(97)00048-3.

[22] Saslawsky DA, Wurtele SK. Educating children about sexual abuse: implications for pediatric intervention and possible prevention. J Pediatr Psychol 1986; 11:235-45. doi:10.1093/ jpepsy/11.2.235.

[23] Tutty LM. What children learn from sexual abuse prevention programs: difficult concept and developmental issues. Res Soc Work Pract 2000; 10:275-300. doi:10.1177/104.973.15000100 0301.

[24] Wolfe DA, MacPherson T, Blount R, Wolfe VV. Evaluation of a brief intervention for educating school children in awareness of physical and sexual abuse. Child Abuse Negl 1986; 10:8592. doi:10.1016/0145-2134(86)90036-0. 